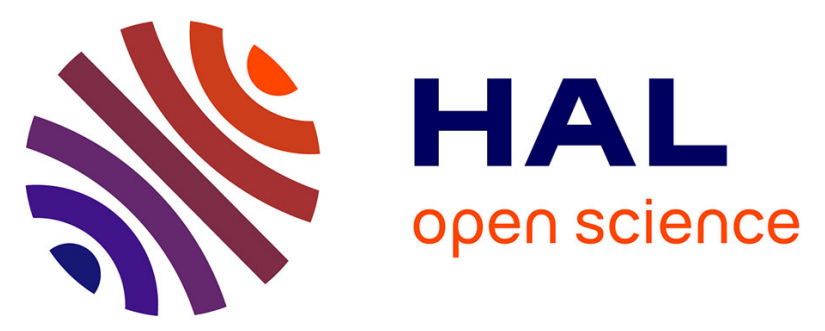

\title{
Design and testing of a 5GHz TE10-TE30 mode converter mock-up for the lower hybrid antenna proposed for ITER
}

Julien Hillairet, Joëlle Achard, Stéphane Rasio, Bernard Soler, Cyril Brun

\section{- To cite this version:}

Julien Hillairet, Joëlle Achard, Stéphane Rasio, Bernard Soler, Cyril Brun. Design and testing of a 5GHz TE10-TE30 mode converter mock-up for the lower hybrid antenna proposed for ITER. Fusion Engineering and Design, 2012, 87 (3), pp.275-280. 10.1016/j.fusengdes.2012.01.007 . cea-02459704

\section{HAL Id: cea-02459704 https://hal-cea.archives-ouvertes.fr/cea-02459704}

Submitted on 29 Jan 2020

HAL is a multi-disciplinary open access archive for the deposit and dissemination of scientific research documents, whether they are published or not. The documents may come from teaching and research institutions in France or abroad, or from public or private research centers.
L'archive ouverte pluridisciplinaire $\mathbf{H A L}$, est destinée au dépôt et à la diffusion de documents scientifiques de niveau recherche, publiés ou non, émanant des établissements d'enseignement et de recherche français ou étrangers, des laboratoires publics ou privés. 


\title{
Design and Testing of a $5 \mathrm{GHz} \mathrm{TE}_{10}-\mathrm{TE}_{30}$ Mode Converter Mock-Up for the Lower Hybrid Antenna proposed for ITER
}

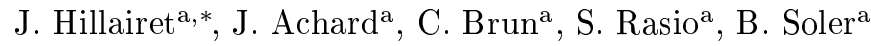 \\ ${ }^{a}$ CEA, IRFM, F-13108 Saint Paul-lez-Durance, France
}

\begin{abstract}
The design and overall dimensions of a $5 \mathrm{GHz} \mathrm{TE}_{10}-\mathrm{TE}_{30}$ mode converter are presented. This mode converter is a RF element of a $20 \mathrm{MW} \mathrm{CW} \mathrm{Lower}$ Hybrid system proposed for ITER. A low power mock-up of this device has been manufactured at CEA/IRFM and measured at low power. RF measurements indicate a return loss of $40 \mathrm{~dB}$ and a transmission loss of $4.78 \mathrm{~dB} \pm 0.03 \mathrm{~dB}$ for the three outputs. The forward conversion efficiency from $\mathrm{TE}_{10}$ mode to $\mathrm{TE}_{30}$ has been measured from electric field probing to $99.9 \%$. The good RF performances obtained validate the RF design of this element.
\end{abstract}

Keywords: Lower Hybrid, Current Drive, LHCD, ITER, Mode Converter

\section{Introduction}

Following the ITER Science and Technical Adivisory Committee recommendation, the conceptual design, the $\mathrm{R} \& \mathrm{D}$ program, the procurement and the installation of a Lower Hybrid Current Drive (LHCD) system on ITER had been reviewed[1]. A revised $5 \mathrm{GHz}$ LHCD system able to deliver $20 \mathrm{MW} / \mathrm{CW}$ on ITER and to sustain the expected high heat fluxes coming from the plasma radiation, particles fluxes and $\mathrm{RF}$ losses has been reported[2, 3]. In this frame, a R\&D effort is currently on-going at CEA/IRFM on the different elements of the antenna. In this paper, we report the work made concerning the design and low power $\mathrm{RF}$ test of a $\mathrm{TE}_{10}-\mathrm{TE}_{30}$ mode converter.

\section{General Description of the ITER LH Antenna}

The LH launcher design presently foreseen for ITER is a Passive-Active Multijunction (PAM), which has been successfully validated on FTU[4] at $8 \mathrm{GHz}$ and on Tore Supra[5, 6] at $3.7 \mathrm{GHz}$. The nominal refractive parallel index $n_{\|}$

\footnotetext{
${ }^{*}$ Corresponding author

Email address: julien.hillairet@cea.fr (J. Hillairet)
} 
excited by the coupling structure has been determined from integrated simulations of propagation and absorption of LH waves in ITER for several scenarios. These simulations showed that an optimum $\left|n_{\|}\right|$, defined as a trade-off between maximizing the current drive efficiency and minimizing the power deposition in the H-mode pedestal, is found to be $\left|n_{\|}\right|=[1.9-2.0]$ with a flexibility of $[1.8-2.2][7,8]$.

In the present design, the launcher is made of 48 identical modules, each one independently fed by one klystron: twelve in the toroidal direction and four in the poloidal direction. A module consists of four active waveguides in the toroidal direction and six lines of waveguides in the poloidal direction (Figure 1)[2]. The RF power is carried through a transmission line up to a RF window located inside the frame and connected to a poloidal $3 \mathrm{~dB}$ splitter which feeds two $\mathrm{TE}_{10}-\mathrm{TE}_{30}$ mode converters. Each of these mode converters converts the incident power from the rectangular $\mathrm{TE}_{10}$ mode to the rectangular $\mathrm{TE}_{30}$ mode in order to further divide the power into three poloidal rows, corresponding to the input of a 4-active waveguides Passive Active Multijunction. In the next section, we describe the design, the mock-up manufacturing and the low power $\mathrm{RF}$ tests of the mode converter.

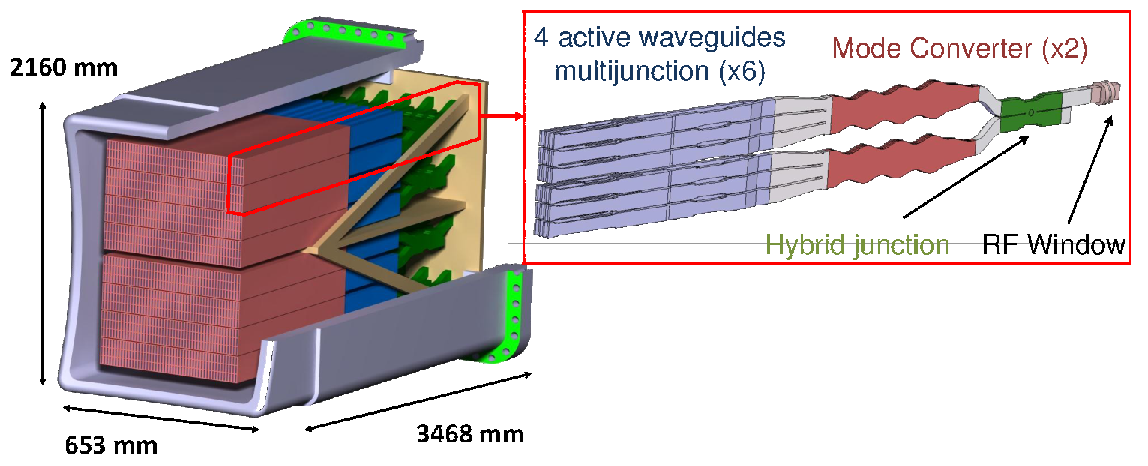

Figure 1: Left: General CAD view of the ITER LH antenna. Right: RF CAD modeling of a module. The antenna is made of 48 identical modules. The RF power is coming from a $500 \mathrm{~kW}$ RF source located at the right of the figure, through the RF window, the hybrid junction, the two mode converters and the six PAM multijunctions. All the elements of a module located behind the RF window are under the machine vacuum.

\section{3. $\mathrm{TE}_{10}-\mathrm{TE}_{30}$ mode converter}

\subsection{Introduction}

The aim of the $\mathrm{TE}_{10}-\mathrm{TE}_{30}$ mode converter is to convert an input fundamental Transverse Electric ( $\mathrm{TE})$ rectangular mode $\left(\mathrm{TE}_{10}\right)$ into an other rectangular mode (the $\mathrm{TE}_{30}$ mode). This conversion is then used in order to equally split the power in three in an adapted splitter. Such splitting scheme, used in both Tore Supra LH antennas since 1999, is achieved by a perturbation of the waveguide geometry leading to mode coupling. Fundamental input $\mathrm{TE}_{10}$ mode can thus be 
almost totally converted to the $\mathrm{TE}_{30}$ mode, which ideally distributes the power into three in the H-plane[9, 10]. This wall perturbation mode conversion has been used originally on ECRH, where high-order modes are not suitable for long distance transmission and plasma heating [11, 12]. Propagation of guided field into small perturbated wall waveguides can be modeled with the Generalized Telegraphist's equation [13-17]. The resulting set of equations can be solved numerically [18, 19] or almost analytically with some approximations $[15,16]$. We refer to the previous citations for more details on the calculation principles.

\subsection{RF modeling}

\subsubsection{Mode Converter}

In this section we describe the mode converter design. The schematic drawing of a $\mathrm{H}$-plane sinusoidal perturbated wall mode converter is illustrated in Figure 2. In Figure 2, the input $\mathrm{TE}_{10}$ mode is coming from the left. Input width $a_{0}$ must be set sufficiently large in order to permit the $\mathrm{TE}_{30}$ mode to propagate, leading to $a_{0} \geqslant 90 \mathrm{~mm}$ at $5 \mathrm{GHz}$. Output width $a_{1}$ is set to insure the $\mathrm{TE}_{50}$ mode to cut-off, i.e. $a_{1} \leqslant 150 \mathrm{~mm}$. The $\mathrm{TE}_{40}$ modes is able to propagate at the output width $a_{1}$, however, an incident odd TE mode upon an $\mathrm{H}$-plane discontinuity with a longitudinal symmetry only excites odd TE modes in rectangular waveguides. A similar conclusion is obtained in the case of even modes (see Ref.[20] for an elegant derivation of this property).

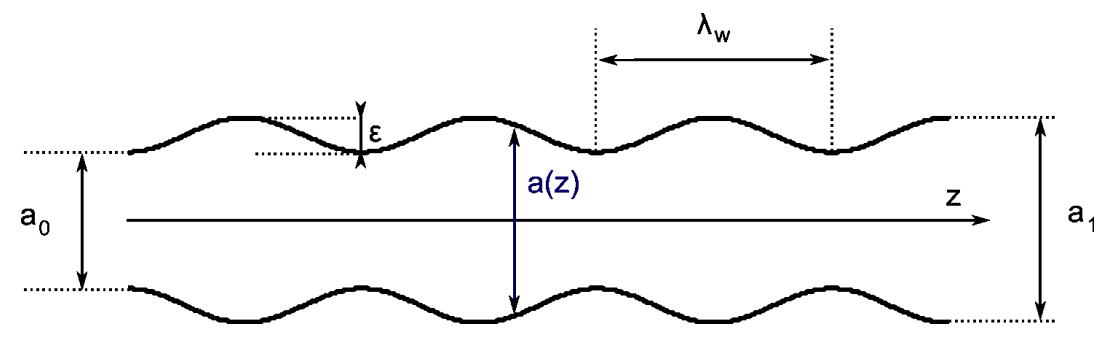

Figure 2: Schematic drawing (H-plane cut) of the $\mathrm{TE}_{10}-\mathrm{TE}_{30}$ mode converter.

The mode evolution along the mode converter is obtained by solving the generalized telegraphist's equations for a 3.5 periods deformed waveguide of wavelength $\lambda_{w}$ defined by the following sinusoidal perturbation[9, 17, 21]:

$$
a(z)=a_{0}+\varepsilon\left(1-\cos \left(\frac{2 \pi}{\lambda_{w}} z\right)\right)
$$

In order to reach the best mode conversion to $\mathrm{TE}_{30}$ mode, a numerical optimization of parameters $a_{0}, \varepsilon$ and $\lambda_{w}$ has been made in Matlab using a Generalized Telegraphist's equation solver. This first optimization led to dimensions $a_{0}=98 \mathrm{~mm}, \varepsilon=22.4 \mathrm{~mm}$ and $k_{w}=2 \pi / \lambda_{w}=36.3059 \mathrm{~m}^{-1}$.

Further optimization of these parameters have been made into HFSS, taking into account RF conduction losses on walls. In order to avoid spurious mode generation or numerical instabilities, some extra straight rectangular waveguides 
have been added at the input and output of the HFSS model (Figure 3). This optimization led to the dimensions reported in Table 1, which are very close to the ones found in Matlab.

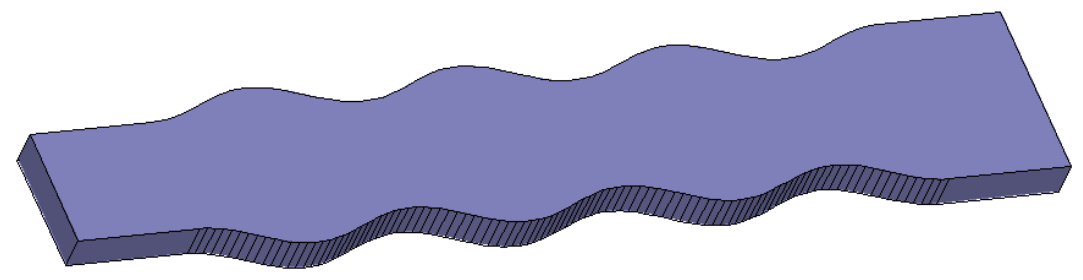

Figure 3: HFSS RF model of the mode converter (without taper at the input).

\begin{tabular}{|c|c|}
\hline$a_{0}[\mathrm{~mm}]$ & 98 \\
\hline$\varepsilon[\mathrm{mm}]$ & 22.37 \\
\hline$\lambda_{w}=\frac{2 \pi}{k_{w}}[\mathrm{~mm}]$ & 173.06 \\
\hline$k_{w}\left[\mathrm{~m}^{-1}\right]$ & 36.3059 \\
\hline$L\left(=3.5 \lambda_{w}\right)[\mathrm{mm}]$ & 605.71 \\
\hline$a_{1}=a_{0}+2 \varepsilon[\mathrm{mm}]$ & 142.8 \\
\hline
\end{tabular}

Table 1: Dimensions of a $5 \mathrm{GHz} 3.5$ periods $\mathrm{TE}_{10}-\mathrm{TE}_{30}$ mode converter.

The return loss for the fundamental mode is $20.5 \mathrm{~dB}$. Propagation losses for copper plating walls, calculated as $1-\sum_{j}\left|S_{j 1}\right|^{2}$, is $1.36 \%$. The bandwidth of the device, defined as the range of frequencies for which at least $95 \%$ of the $\mathrm{TE}_{10}$ mode is converted to $\mathrm{TE}_{30}$, is $120 \mathrm{MHz}$. Electric field into the mode converter is illustrated in Figure 4. The length of the device is, without taking into account input and output straight rectangular waveguides, $606 \mathrm{~mm}$.

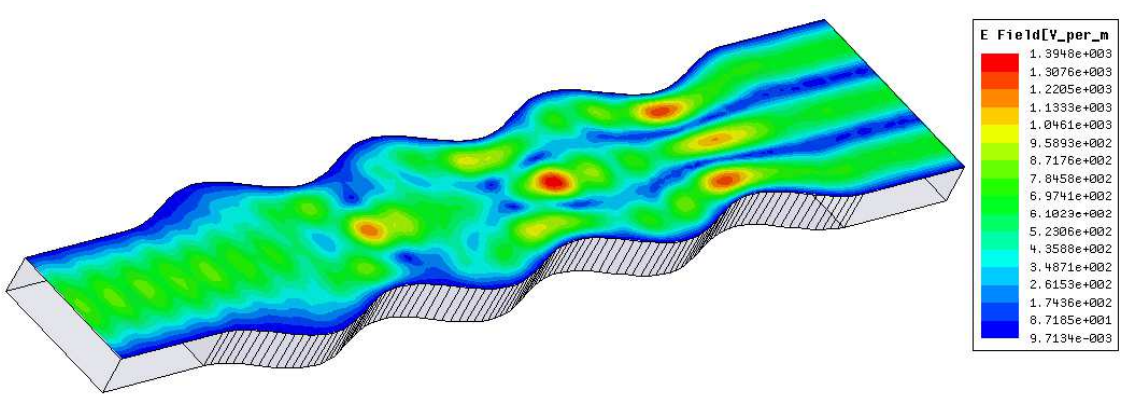

Figure 4: Norm of the electric field $[\mathrm{V} / \mathrm{m}]$ in the mode converter $\left(P_{\text {in }}=1 \mathrm{~W}\right)$.

In order to feed the mode converter with a standard WR-229 waveguide ( $a=58.17 \mathrm{~mm}, b=29.08 \mathrm{~mm}$ ), an input taper has to be added to match the WR-229 width. This taper is described in the next section. 


\subsection{Input Taper}

In order to make the transition between the input width $a_{0}$ of the mode converter and the conventional waveguide WR-229 width which is $58 \mathrm{~mm}$, an extra taper must be added at the input (instead of the straight rectangular waveguide used before). A cosine taper has been modeled with the following width equation:

$$
a(z)=\frac{1}{2}\left(a_{\mathrm{WR} 229}+a_{0}\right)+\frac{1}{2}\left(a_{\mathrm{WR} 229}+a_{0}\right) \cos \left[\left(\frac{z}{L_{\text {taper }}}-1\right) \pi\right]
$$

where $L_{\text {taper }}$ is the total length of the taper, $a_{\text {WR229 }}$ is the WR-229 width $(58.17 \mathrm{~mm})$ and $a_{0}$ the input width of the mode converter. The model has been drawn in HFSS and then optimized in order to minimize return loss and mode conversion to $\mathrm{TE}_{30}$ which is unwanted at this stage. With a length of $L_{\text {taper }}=120 \mathrm{~mm}$, S-parameters are reported in the Table 2 below.

\begin{tabular}{|c|c|c|}
\hline \multicolumn{2}{|r|}{$\left|S_{11}\right|$ with $\mathrm{TE}_{10}$ input } & $-59.7 \mathrm{~dB}(0.00104)$ \\
\hline $\mid S_{21}$ & with $\mathrm{TE}_{10}$ input and $\mathrm{TE}_{10}$ output & $-0.014 \mathrm{~dB}(0.99839)$ \\
\hline $\mid S_{21}$ & with $\mathrm{TE}_{10}$ input and $\mathrm{TE}_{20}$ output & $-80 \mathrm{~dB}(0.00010)$ \\
\hline $\mid S_{21}$ & with $\mathrm{TE}_{10}$ input and $\mathrm{TE}_{30}$ output & $-25.7 \mathrm{~dB}(0.05208)$ \\
\hline
\end{tabular}

Table 2: Cosine Taper scattering parameters at $5 \mathrm{GHz}$.

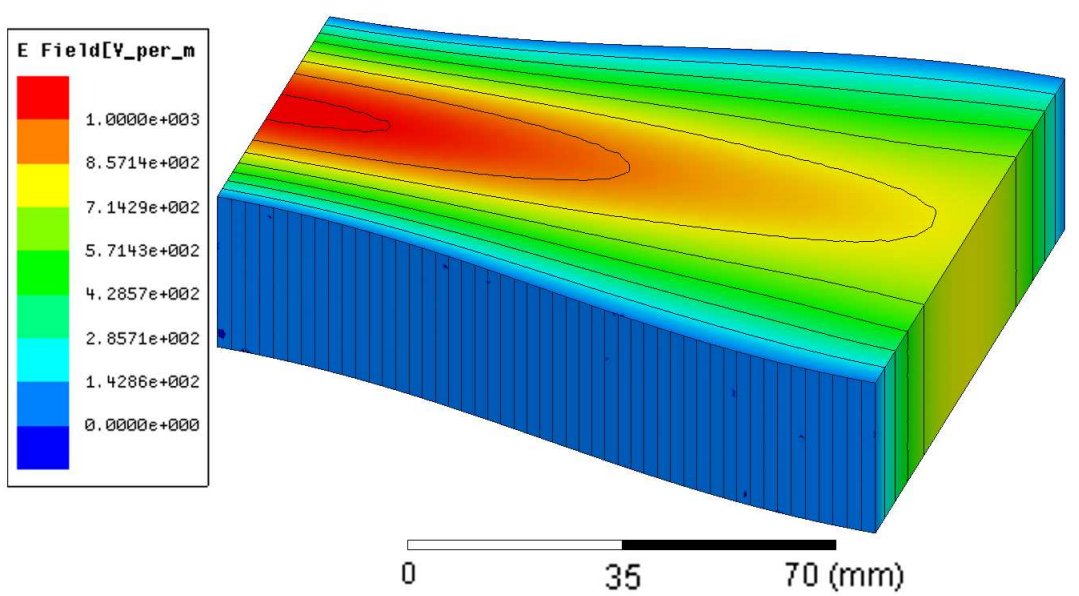

Figure 5: HFSS RF model of the $5 \mathrm{GHz}$ cosine taper, electric field norm $[\mathrm{V} / \mathrm{m}]$ for $P_{i n}=1 \mathrm{~W}$.

\subsection{Mode converter and input taper}

The combination of the taper and the mode converter has been modeled in HFSS. The model consists in the taper and the mode converter plus two straight 
$20 \mathrm{~mm}$ waveguides at the input and output of the device (Figure 6). Scattering parameters are reported in Table 3 . Let us define the forward mode conversion efficiency as the ratio between the power carried by the $\mathrm{TE}_{30}$ over the total forward power. According to the S-parameters, the theoretical mode conversion efficiency is close of $99.5 \%$.

The electric field inside the device is illustrated in Figure 6. Considering an input nominal power of $250 \mathrm{~kW}$, the maximum electric field reached into the mode converter is $6.9 \mathrm{kV} / \mathrm{cm}$ (Figure 6). The bandwidth, as previously defined, is $120 \mathrm{MHz}$ (Figure 7). The total length of the device is $725.7 \mathrm{~mm}$.

\begin{tabular}{|c|c|c|}
\hline Parameter & $5 \mathrm{GHz}$ HFSS & $3.7 \mathrm{GHz}$ (Tore Supra C4) \\
\hline \hline$S_{11} \mathrm{TE}_{10}$ & $-20.5 \mathrm{~dB}$ & $-17.7 \mathrm{~dB}$ \\
\hline$S_{21} \mathrm{TE}_{10}$ & $-23 \mathrm{~dB}$ & $-33.6 \mathrm{~dB}$ \\
\hline$S_{21} \mathrm{TE}_{20}$ & $-69.1 \mathrm{~dB}$ & $-81.9 \mathrm{~dB}$ \\
\hline$S_{21} \mathrm{TE}_{30}$ & $-0.064 \mathrm{~dB}$ & $-0.0935 \mathrm{~dB}$ \\
\hline Length $[\mathrm{mm}]$ & 725.7 & 944 \\
\hline Max. E-field $[\mathrm{kV} / \mathrm{cm}]$ & 6.9 & 5.8 \\
\hline
\end{tabular}

Table 3: Scattering parameters of the Cosine Taper + Mode Converter (HFSS). For comparison purpose, Tore Supra mode converter results are reported. Maximum electric field has been calculated for $P_{i n}=250 \mathrm{~kW}$.

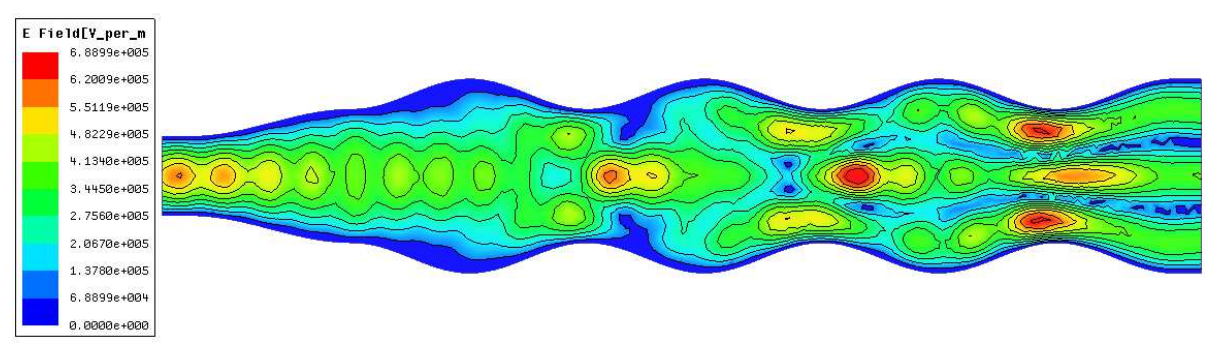

Figure 6: Illustration of the norm of the electric field $[\mathrm{V} / \mathrm{m}]$ into the mode converter with its input taper $\left(P_{\text {in }}=250 \mathrm{~kW}\right)$.

\subsection{Poloidal splitter}

The poloidal splitter aims to split the power coming from the mode converter, which is mainly a pure $\mathrm{TE}_{30}$ mode, into three distinct waveguide sections. This poloidal divider is illustrated in Figure 8. It has been optimized first alone in order to maximize the power splitting when exciting with a $\mathrm{TE}_{30}$ mode, then with the mode converter fastened.

The calculated scattering parameters of this device are reported in Table 4.

\subsection{Complete assembly}

The complete assembly, i.e. the mode converter associated to its input taper and the poloidal splitter has been modeled in HFSS. The calculated return loss 


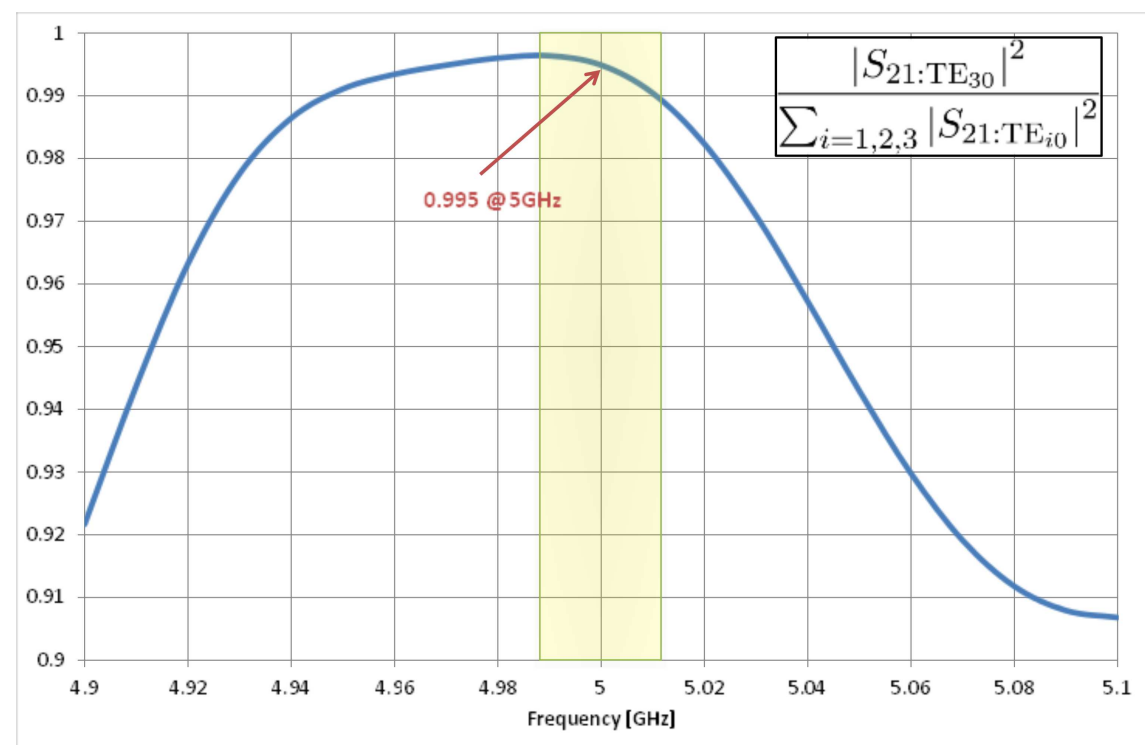

Figure 7: S-parameter conversion efficiency, defined as $\left|S_{21}\right|^{2}$ for $\mathrm{TE}_{30}$ mode over over the total forward power vs frequency. The typical operational bandwidth of a klystron is $\pm 10 \mathrm{MHz}$, as illustrated on the figure.

\begin{tabular}{|c|c|}
\hline Parameter & $5 \mathrm{GHz}$ HFSS \\
\hline \hline$S_{11}$ for $\mathrm{TE}_{30}$ & $-46.3 \mathrm{~dB}$ \\
\hline$S_{i 1}$ for $\mathrm{TE}_{30}$ & $-4.81 \mathrm{~dB}$ \\
\hline
\end{tabular}

Table 4: Scattering parameters of the poloidal splitter.

is $45.5 \mathrm{~dB}$. The transmission losses are $4.79 \mathrm{~dB} \pm 0.01 \mathrm{~dB}$ for the three ports, close to the ideal value $4.77 \mathrm{~dB}$ which corresponding to the third of the input power. The scattering parameters evolution on a 4.9-5.1 GHz frequency band are reported in the final section.

\section{Mock-up manufacturing}

A low power mock-up of this $5 \mathrm{GHz}$ mode converter (with its input taper) has been manufactured at CEA/IRFM using a 2-axis numerical drilling machine in Aluminum directly from the CATIA CAD model. The poloidal splitter as well as some other waveguide elements used only for measurement purposes, such as the "pull-over" described in the next section, have been manufactured by the SUMIX company from the CAD models. The top of each elements has been screw tight in order to insure a very good RF contact (Figure 9). 


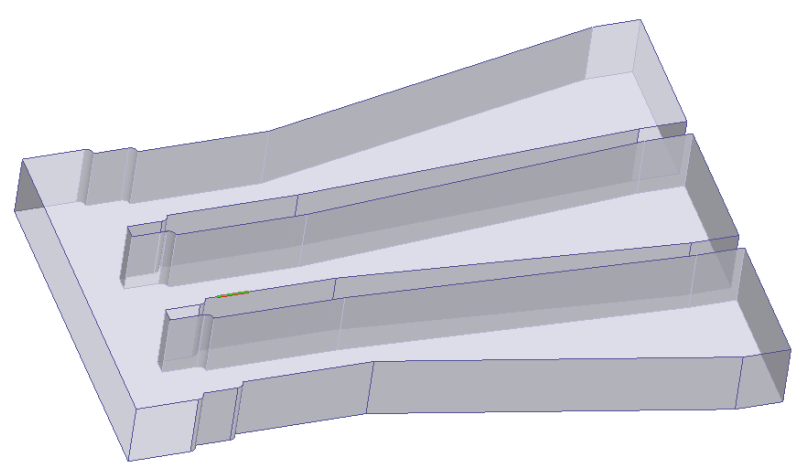

Figure 8: RF CAD of the poloidal splitter.

\section{Low Power RF Measurements}

The test bed used to measure the mode converter consisted in the assembly of the mode converter, the poloidal splitter and the "pull-over". The aim of this last element is only to facilitate the measurements by putting the output ports aside. Some WR187-WR229 tapers have also been added at each ports in order to match the commercially available WR187 waveguide-to-coaxial transitions (Figure 10).

RF measurements indicate a return loss of $40 \mathrm{~dB}$ and a transmission loss of $4.78 \mathrm{~dB} \pm 0.03 \mathrm{~dB}$ for the three ports, very close from the ideal $4.77 \mathrm{~dB}$ corresponding to the third of the input power. Amplitude measurement results are illustrated in Figures 11 and 12; results are in good agreement with the numerical modeling of the complete assembly. The phase shift between the side ports and the center port is $180 \mathrm{deg} \pm 5 \mathrm{deg}$ as expected by the modeling.

In order to measure the forward conversion efficiency from $\mathrm{TE}_{10}$ mode to $\mathrm{TE}_{30}$, a dedicated waveguide element has been manufactured. This element allows direct electric field probing of the mode converter output section, in which an almost pure $\mathrm{TE}_{30}$ mode is expected. This element is illustrated in Figures 9 and 10. It consists in a straight waveguide of section $142.8 \mathrm{~mm} \times 29.08 \mathrm{~mm} \times$ $308 \mathrm{~mm}$, which matches the output section of the mode converter. Three rows of holes ( $2 \mathrm{~mm}$ diameter, $10 \mathrm{~mm}$ spaced) are drilled in the H-plane. These holes are made to support and block the probe in order to make the measurements at the exactly same spatial locations while holding the probe in a vertical position. The probe is inserted inside each hole sequentially and measures the amplitude and the phase of the electric field inside the waveguide. The coupling element is a thin $1 \mathrm{~mm}$ diameter copper wire. The probe ground potential is connected to the waveguide. The coupling has been measured to be $-49 \mathrm{~dB}$. Once the probe is inserted into a probe hole, the coupling element supersedes the waveguide wall by less than $1 \mathrm{~mm}$. It is supposed from the small dimensions of the probe that the perturbations due to its use are negligible.

From these electric field measurements, the modal content after the mode 


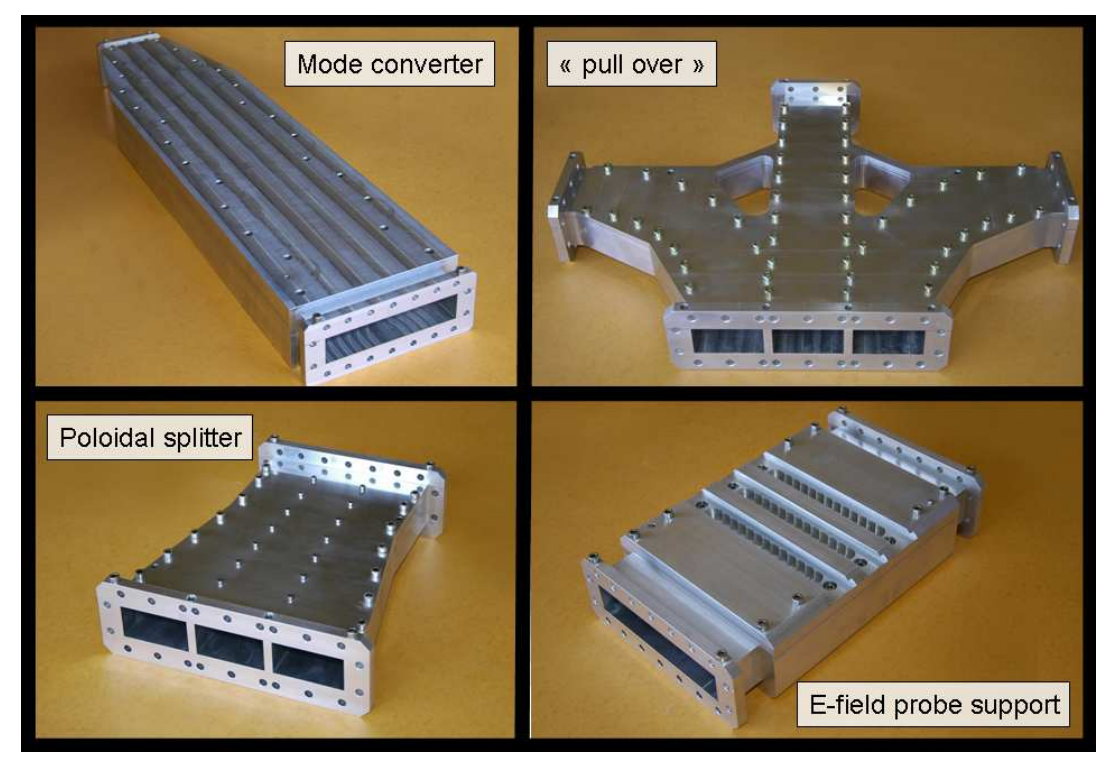

Figure 9: Manufactured low RF power mock-up elements. From top left to bottom right: mode converter, "pull-over" and E-field probe waveguide support.

converter can then be deduced with the following method. We first assume that the electromagnetic field inside the waveguide is a linear combination of $\mathrm{TE}_{m 0}$ modes, ie. at a point $(x, z)$ of the waveguide:

$$
E_{t h}(x, z)=\sum_{m=1}^{N_{m o d e s}} A_{m} e_{m}^{+}(x, z)+B_{m} e_{m}^{-}(x, z)
$$

where $x$ is the largest side direction and $z$ is the propagation direction. The $e_{m}^{ \pm}$ terms are the analytic modal eigunfunctions describing forward and backward $\mathrm{TE}_{m 0}$ modes shapes. Analytical expressions of the modal functions can be found in [22] for example. $A_{m}$ and $B_{m}$ are the associated forward and backward weight coefficients. The aim of the method is to find the $2 \times N_{\text {modes }}$ best coefficients $A_{m}, B_{m}$ in order to minimize the squares of the error $\chi^{2}$ between the theoretical field and the measured field:

$$
\chi^{2}\left(A_{m}, B_{m}\right)=\sum_{i=1}^{N_{m e s}}\left(E_{m e s, i}-E_{t h, i}\right)^{2}
$$

Solving this problem leads to the forward $A_{m}$ and backward $B_{m}$ coefficients, and thus to the forward mode conversion efficiency which can be defined as the ratio between the power carried by the $\mathrm{TE}_{30}$ over the power carried by all forward modes, i.e:

$$
\eta=\frac{\left|A_{3}\right|^{2}}{\sum_{n}\left|A_{n}\right|^{2}} \times 100
$$




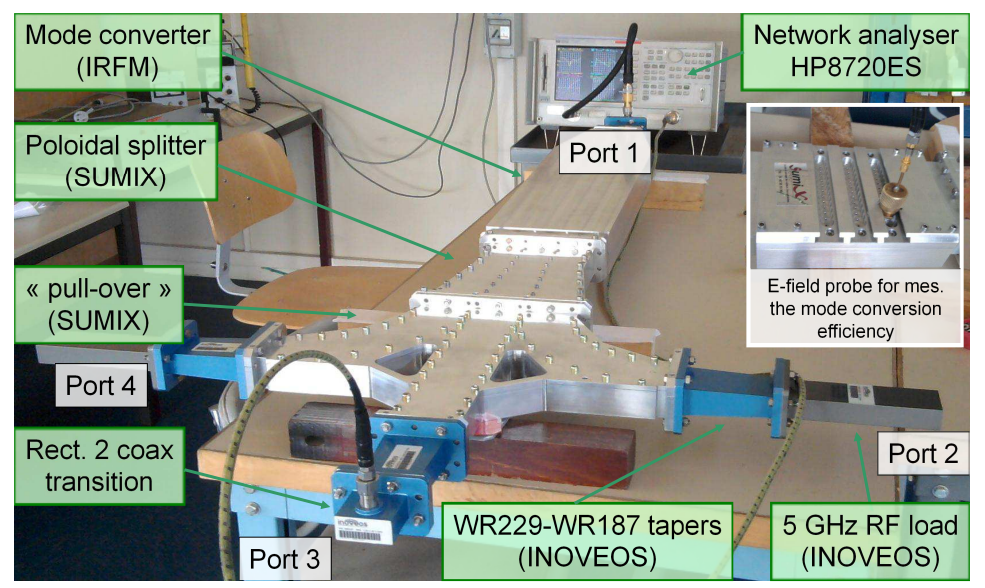

Figure 10: RF test bed. The pull-over (bent connection waveguides) and the E-field probe support are only used for low-power RF measurements.

This efficiency has been calculated from the electric field probing after the mode converter to be $\eta=99.9 \%$.

\section{Conclusion}

In the frame of the Lower Hybrid R\&D for ITER activities conducted at CEA/IRFM, a low power mock-up of a $\mathrm{TE}_{10}-\mathrm{TE}_{30}$ mode converter at $5 \mathrm{GHz}$ has been designed, manufactured and successfully validated with low power RF measurements. Further work will concentrate on thermo-mechanical aspects relevant to ITER operational conditions (high power aspects, cooling, pumping) of this mode converter. Other RF elements of the ITER LH antenna, such as the RF windows, are as well under study and manufacturing for qualification.

Acknowledgments. The authors acknowledge the support of the SUMIX company. This work, supported by the European Communities under the contract of Association between EURATOM and CEA, was carried out within the framework of the European Fusion Development Agreement. The views and opinions expressed herein do not necessarily reflect those of the European Commission.

[1] G. T. Hoang, et al., A Lower Hybrid Current Drive System for ITER, Nuclear Fusion 49 (7), doi:10.1088/0029-5515/49/7/075001.

[2] J. Hillairet, et al., RF modeling of the ITER relevant lower hybrid antenna, Fusion Engineering and Design In Press, Corrected Proof, ISSN 0920-3796.

[3] L. Marfisi, et al., Thermal and mechanical analysis of ITER-relevant LHCD antenna elements, Fusion Engineering and Design In Press, Corrected Proof, ISSN 0920-3796. 


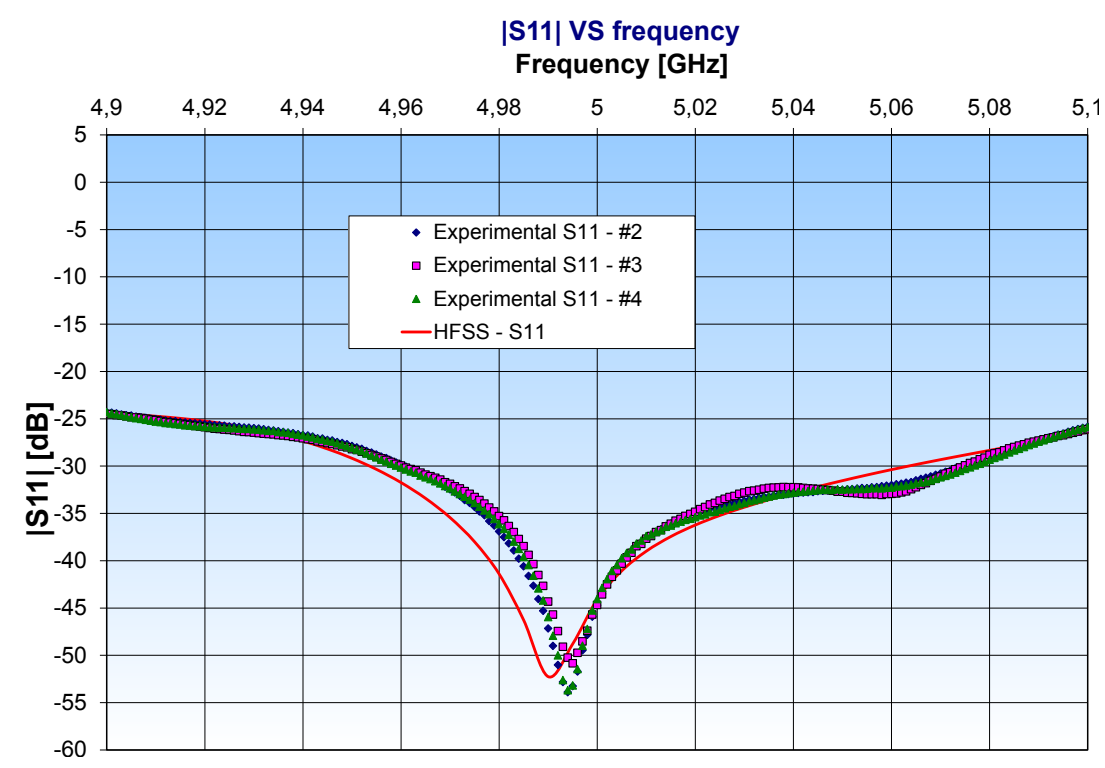

Figure 11: Reflexion scattering parameter $\left|S_{11}\right|$ of the mode converter over the $4.9-5.1 \mathrm{GHz}$ frequency band. HFSS modeling results are illustrated for comparison. Three measurements have been made, corresponding to the network analyzer second port location on port 2,3 or 4 .

[4] V. Pericoli-Ridolfini, P. Bibet, F. Mirizzi, M. Apicella, E. Barbato, P. Buratti, G. Calabro, A. Cardinali, G. Granucci, L. Panaccione, S. Podda, C. Sozzi, A. Tuccillo, LHCD and coupling experiments with an ITER-like PAM launcher on the FTU tokamak, Nuclear Fusion 45 (9) (2005) 1085, URL http://stacks .iop.org/0029-5515/45/i=9/a=008.

[5] A. Ekedahl, et al., Validation of the ITER-relevant passive-active-multijunction LHCD launcher on long pulses in Tore Supra, Nuclear Fusion 50 (11), doi:10.1088/0029$5515 / 50 / 11 / 112002$

[6] A. Ekedahl, et al., Long pulse operation with the ITER-relevant LHCD antenna in Tore Supra,, in: 19th RF topical Newport, 2011.

[7] A. Becoulet, et al., Steady State Long Pulse Tokamak Operation Using Lower Hybrid Current Drive, in: 26th SOFT, 2010.

[8] J. Decker, Y. Peysson, J. Hillairet, J.-F. Artaud, V. Basiuk, A. Becoulet, A. Ekedahl, M. Goniche, G. Hoang, F. Imbeaux, A. Ram, M. Schneider, Calculations of lower hybrid current drive in ITER, Nuclear Fusion 51 (7) (2011) 073025, URL http://stacks . iop.org/0029-5515/51/i=7/a=073025.

[9] P. Bibet, T. Nguyen, J. Achard, G. Berger-By, S. Berio, M. Goniche, G. Rey, G. Tonon, Experimental and Theoretical Results Concerning the Development of the Main RF Components for Nest Tore Supra LHCD Antennae, in: Proceeding of the 18th SOFT Conference, vol. 1, 1994.

[10] X.-J. Wang, F.-K. Liu, L.-M. Zhao, H. Jia, H.-B. Liu, G.-L. Kuang, Design of a TE10TE30 Rectangular Mode Converter for 4.6 GHz LHCD Launcher in the Experimental Advanced Superconducting Tokamak, Chinese Physics Letters 26 (2) (2009) 025202, URL http://stacks . iop.org/0256-307X/26/i=2/a=025202. 


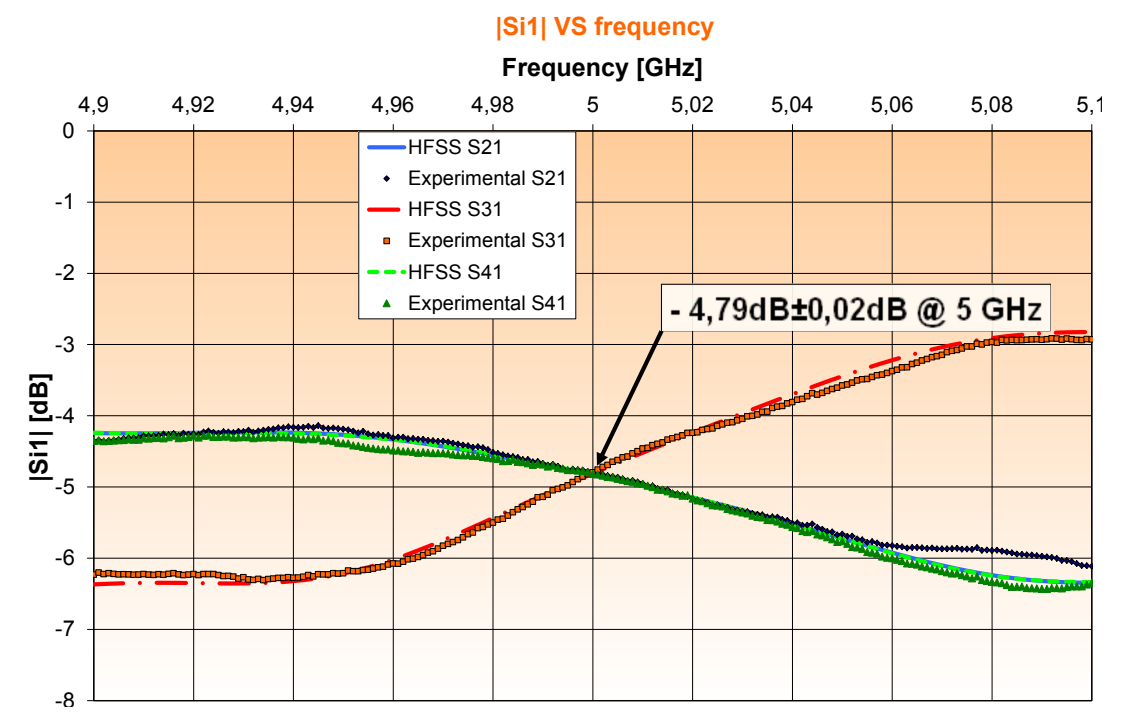

Figure 12: Transmission scattering parameters $\left|S_{i 1}\right|$ of the mode converter over the 4.9$5.1 \mathrm{GHz}$ frequency band $(i \in\{2,3,4\})$. HFSS modeling results are illustrated for comparison.

[11] M. Thumm, H. Kumric, H. Stickel, TE03 to TE01 mode converters for use with a $150 \mathrm{GHz}$ Gyrotron, International Journal of Infrared and Millimeter Waves 8 (3) (1987) 227-240.

[12] M. Thumm, W. Kasparek, Passive high-power microwave components, IEEE Trans. Plasma Science 30 (3) (2002) 755- 786.

[13] S. Schelkunoff, Generalized Telegraphist's Equations for Waveguides, Bell System Tech. J. (1952) 784-801.

[14] S. A. Schelkunoff, Conversion of Maxwell's Equations into Generalized Telegraphist's Equations, Bell System Tech. J. 34 (1955) 995-1043.

[15] H.-G. Unger, Waveguide Taper of Improved Design, Bell System Tech. J. 37 (1958) 899912.

[16] L. Solymar, Spurious Mode Generation in Nonuniform Waveguide, IRE Trans. Microwave Theory and Techniques (1959) 379-383.

[17] M. Buckley, R. Vernon, Compact quasi-periodic and aperiodic TE0n modeconverters in overmoded circular waveguides for use with gyrotrons, IEEE Trans. Microwave Theory and Techniques 38 (6) (1990) 712-721.

[18] H. Flugel, E. Kuhn, Computer-aided analysis and design of circular waveguide tapers, IEEE Trans. Microwave Theory and Techniques 36 (2) (1988) 332-336.

[19] W. Huting, K. Webb, Numerical Analysis of Rectangular and Circular Waveguide Tapers, IEEE Trans. Magnetics 25 (4) (1989) 3095-3097.

[20] R. Dusséaux, P. Chambelin, C. Faure, Analysis Of Rectangular Waveguide H-Plane Junctions In Nonorthogonal Coordinate System, Progress In Electromagnetics Research 28 (2000) 205-229. 
[21] F. Wang, Note on the asymptotic approximation of a double integral with an angular spectrum representation, AEU - International Journal of Electronics and Communications 59 (4) (2005) 258-261.

[22] R. E. Collin, Field Theory of Guided Waves, IEEE Press, New York, 1990. 